\title{
Nuevas formas de intervención en la cuestión social: la actuación de las organizaciones no gubernamentales en las políticas sociales en la ciudad de posadas misiones argentina
}

\author{
Susana Moniec* \\ Rosario González ${ }^{* *}$
}

\begin{abstract}
RESUMEN
Las nuevas tendencias de la política social rescatan modelos de Estados de Bienestar de carácter pluralista, en los cuales un papel importante en la provisión del bienestar, además del Estado y el mercado, es asignado a la sociedad civil, a la que se le atribuye la capacidad de intervenir en una distribución más eficaz de los recursos por estar alejada de las prácticas propias y ancestrales del Estado, como por ejemplo, las de carácter clientelar, en la prestación de asistencia. En la Argentina y en particular en Misiones, la mayoría de los programas de política social del Estado recurren para su instrumentación a las organizaciones de la sociedad civil que en las últimas décadas se han incrementado abruptamente. Por ello, en este trabajo se pretende incursionar en la caracterización de estas organizaciones a fin de analizar sus capacidades en la prestación del bienestar.
\end{abstract}

Palabras clave: Políticas sociales / Organizaciones de la sociedad civil / Intervención / Trabajo Social.

Novas formas de intervenção na questão social: a actuação das organizações não governamentais nas políticas sociais na cidade de posadas misiones argentina

As novas tendências da política social resgatam modelos de Estados de Bem-estar de carácter pluralista, nos quais um papel importante na provisão do bem-estar, além do Estado e o mercado é atribuído à sociedade civil; à que se lhe atribui a capacidade de intervir numa distribuição mais eficaz dos recursos por estar afastada das práticas próprias e ancestrales do Estado, como por exemplo, as de carácter clientelar, na prestação de assistência. $\mathrm{Na}$

* Argentina. Trabajadora Social. Docente e investigadora del Departamento de Trabajo Social. Facultad de Humanidades y Ciencias Sociales. Universidad Nacional de Misiones, Argentina. Correo electrónico: sumoniec@invs.unam.edu.ar

** Argentina. Trabajadora Social. Docente e investigadora del Departamento de Trabajo Social. Facultad de Humanidades y Ciencias Sociales. Universidad Nacional de Misiones, Argentina. Correo electrónico:rosario_gonzalezl@yahoo.com 
Nuevas formas de intervención en la cuestión social: la actuación de las organizaciones no gubernamentales en las políticas sociales en la ciudad de Posadas Misiones Argentina / Susana Moniec; Rosario González

Argentina e em particular em Missões, a maioria dos programas de política social do Estado recorrem para sua instrumentação às organizações da sociedade civil que nas últimas décadas se incrementaram abruptamente. Por isso, neste trabalho se pretende incursionar na caracterização destas organizações a fim de analisar suas capacidades na prestação do bemestar.

Palavras chave: Políticas sociais / Organizações da sociedade civil / Intervenção / Trabalho Social.

\section{New forms of intervention in the social question: the performance of the no governmental organizations in the social politics in the city of posadas misiones argentina}

\footnotetext{
Recent trends in Social Policy take models from welfare states of a plural character in which an important role in the provision of welfare is assigned not only to the state and the markets but also to the civil society. Moreover civil societies being far from the political machine can intervene in a more equitable distribution of resources thus avoiding political clientelism in the delivery of assistance. In Argentina, and particularly in Misiones most of the state social policies rely on civil society organizations which have increased steadily in the last decades. This paper aims at characterizing these organizations with the intention of analyzing its capability of action in the provision of welfare.
}

Key Words: Social Policies / Civil society organizations / Intervention / Social Work. 


\section{Introducción}

Las nuevas tendencias de la política social rescatan modelos de Estados de Bienestar de carácter pluralista, en los cuales un papel importante en la provisión del bienestar, además del Estado y el mercado, es asignado a la sociedad civil, a la que se le atribuye la capacidad de intervenir en una distribución más eficaz de los recursos por estar alejada de las prácticas propias y ancestrales del Estado, como por ejemplo las de carácter clientelar, en la prestación de asistencia.

En la Argentina y en particular en Misiones la mayoría de los programas de política social del Estado recurren para su instrumentación a las organizaciones de la sociedad civil, que en las últimas décadas se han incrementado abruptamente ${ }^{1}$. En ese sentido en este trabajo interesa incursionar en el análisis de las características que asume la intervención sobre lo social a partir de estas organizaciones. En Misiones, existirían registradas más de 2.200 organizaciones de diverso tipo, entre ellas fundaciones, asociaciones civiles, federaciones, muchas de las cuales surgen a partir de la década del '90. La selección de los casos analizados se realizó a partir de la base de datos sobre organizaciones que maneja el Centro de Referencia del Ministerio de Desarrollo Social en la provincia, considerándose como criterio para la selección, que dichas organizaciones estén involucradas en alguno de los momentos de la implementación de los tres principales programas sociales nacionales que se ejecutan en la provincia de Misiones.

Para el relevamiento de los datos se recurrió a fuentes primarias y secundarias. Entre las primeras se consideraron entrevistas a funcionarios y técnicos de programas de la política social; a responsables del registro y control de las organizaciones de la sociedad civil y a responsables de ONG. Entre las fuentes secundarias, se analizaron documentos impresos y publicados en internet, difundidos por el Ministerio de Desarrollo Social sobre los programas sociales en ejecución en la provincia de Misiones.

1 La lectura y análisis de los datos aquí presentados son preliminares, atendiendo a que la investigación se halla en pleno proceso de desarrollo. 


\section{La década del '90 como disparador: Historia del surgimiento de las ONG en estudio y sus características:}

El total de las organizaciones analizadas se originaron o alcanzaron su apogeo en la década de 1990, coincidentemente con la instalación de los nuevos problemas sociales y los cambios paradigmáticos ocurridos a nivel de las políticas sociales, que son ampliamente indicados en la bibliografía especializada.

Las primeras incursiones de la mayoría de estas organizaciones en el abordaje de la problemática social, se realiza a partir del trabajo voluntario de grupos de personas conocidas, amigas, o vecinas, relacionadas con la iglesia católica local e internacional y vinculadas al campo de las ciencias sociales, interesadas en llevar adelante acciones tendientes a tratar diferentes problemas sociales relacionados con sectores necesitados de la población.

Este trabajo voluntario, rápidamente se institucionaliza, ajustándose a los requerimientos establecidos por los organismos de control, como una estrategia de estas organizaciones para captar los recursos de las políticas sociales.

Respecto a las finalidades que exponen estas organizaciones se destacan el tratamiento de problemáticas sociales como el trabajo, la alimentación, la educación, la salud, la vivienda, etcétera, que afectan a sectores vulnerables, pobres, marginales de la población, y proponiendo como medios o estrategias de intervención la organización, la capacitación, la prevención, la concientización, el cambio de concepciones y prácticas, la orientación y formación, la alfabetización, la asistencia, la articulación, coordinación y canalización de recursos y asistencia técnica y la promoción de los valores del compromiso, la solidaridad, la participación.

Las diferentes finalidades permiten construir una tipología, entre aquellas que oscilan en hacer al bien por amor al prójimo y otras que utilizan su figura jurídica como una forma de hacer sus propios negocios, para lo cual ponen en juego relaciones / contactos con políticos y funcionarios del Estado; contactos y vinculaciones de los cuales va a depender su tamaño y posibilidades de desarrollo, recursos tanto materiales como humanos que manejan y la cantidad de proyectos que desarrollen. 


\section{Requisitos para la constitución y funcionamiento de las ONG}

Respecto a la creación de estas organizaciones, desde los organismos de control del Estado, se exige como uno de los requisitos una cantidad de 50 miembros; para poder dar cuenta de ello los interesados en constituirse en ONG, en general no más de cinco personas, recurren a conocidos, parientes y amigos; una vez reconocida formalmente la organización, en la práctica son dos o tres los integrantes que se encargan del proceso de toma de decisiones y de llevar adelante las principales acciones vinculadas con las actividades en las cuales se manejan fondos. De esta manera, el requisito de cantidad de miembros pasa a constituirse en un mero formalismo. La estrategia de juntar integrantes para reunir la cantidad requerida por los organismos de fiscalización deriva en una tipología de socios que varía según la organización de la cual se trate, que va de una escala de aquellos menos involucrados, que solamente aportan el nombre y en algunos casos la cuota societaria, hasta aquellos que están involucrados en las actividades sustantivas, que son generalmente tres o cuatro socios que ocupan los cargos de presidente, tesorero y secretario y que van rotando en las funciones.

Así, como anteriormente fue mencionado, muchas de las ONG tienen su origen en el trabajo voluntario de sus miembros, de hecho la mayoría de los referentes cuenta con trayectorias de trabajo voluntario a nivel comunitario, trabajo voluntario que al no ser sustentable en el tiempo, se institucionaliza a través de la figura de las ONG, a fin de captar fondos y lograr trabajo rentado. En tanto, cuando los fines de la organización institucionalizada no son posibles de financiamiento de cualquier tipo, recurren a la adecuación de los propios estatutos para acogerse a nuevas líneas de financiamiento que promociona el Estado en la actualidad, resignándose así al sostenimiento de un esquema de trabajo y líneas de acción autónomas.

Se observa entonces que más allá de los objetivos fijados inicialmente por las ONG, las prioridades de intervención que despliegan son condicionadas por el agente financiador, quien termina definiendo la agenda de las organizaciones e incluso la necesidad de la adecuación de sus fines estatutarios. Así también, desde los organismos del Estado se prescribe el ámbito de cobertura y el perfil del usuario. 
En general las ONG, cuentan con diferentes fuentes de financiamiento que varían en su grado de importancia. Fundamentalmente se sostienen con fondos provenientes de diferentes programas sociales como anteriormente se mencionó, los que prevén un porcentaje para gastos operativos. El aporte de los socios es mínimo e irregular y no permite el autofinanciamiento de las organizaciones; en muchas de estas, los gastos fijos para funcionamiento son asumidos por los propios integrantes y en su mayoría utilizan sus domicilios particulares y sus propios recursos a fin de aliviar las erogaciones que éstas demandan. Por su parte los fondos obtenidos son utilizados para la adquisición de bienes (terrenos, maquinarias, herramientas, etcétera), al pago de servicios y contratos a profesionales y para la compra de insumos para su funcionamiento.

\section{El papel / función de las ONG:}

Con relación al papel de la ONG, se observa que más allá de las finalidades y objetivos enunciados en los estatutos, estas organizaciones cumplen múltiples propósitos, entre ellos la función de articular necesidades y recursos; constituirse en espacios alternativos de generación de empleo y autoempleo para sus propios miembros; oficiar como figura jurídica que posibilita, por un lado, a funcionarios políticos del Estado a escapar de los controles de la burocracia y canalizar fondos para diversos fines, y por otro, intermediar para que otras organizaciones de la sociedad civil, no institucionalizadas, puedan ser receptoras de fondos de las diferentes políticas (ejemplo, comedores comunitarios, comisiones vecinales, etcétera).

En relación al rol de articuladora de necesidades y recursos se observa que al demandársele la instrumentación de los programas sociales, éstas se constituyen en intermediarias entre los recursos provistos por diferentes instituciones del Estado o del Mercado y las necesidades que detectan en su ámbito de influencia. A partir de esta vinculación entre necesidades y recursos van construyendo un capital simbólico sobre el cual se auto-promocionan como asociaciones interesadas y preocupadas por los problemas sociales.

La posibilidad de manejo de los recursos del Estado, por parte de estas organizaciones de la sociedad civil, no las exime de que mediante su accionar promuevan relaciones clientelares, similares a las generadas por la clase política en el uso de los recursos públicos, poniendo así en cuestión las posibilidades del 
desarrollo de la ciudadanía, esto es, una concepción de sujeto como portador de derechos antes que receptor de dádivas que deben ser agradecidas.

Por otra parte, se advierte que estas organizaciones funcionan como espacios alternativos de generación de empleo para la población desocupada y de autoempleo para sus propios miembros, quienes se transforman a partir de la instrumentación de diferentes mecanismos, de intermediarios en beneficiarios primarios de los productos / servicios que ofrecen los programas de las políticas sociales.

Para constituirse en beneficiarios de programas sociales, desde las ONG se van generando otras figuras jurídicas (cooperativas fundaciones), adecuándose así a los requerimientos exigidos para la obtención de fondos de programas sociales, pudiendo de este modo desplegar actividades que sus propios fines estatutarios no le permitirían. Si bien esta diversidad de figuras jurídicas permite la captación de fondos y el despliegue de diferentes estrategias, en la práctica la dispersión de esfuerzos de pocos miembros en una diversidad de iniciativas, no siempre se sostienen en el tiempo, haciendo ineficiente el accionar de las organizaciones.

Así, muchos de los proyectos rentados encarados por las asociaciones y financiados por fondos de los programas sociales, más allá de los objetivos sustantivos, constituyen mecanismos de generación de auto- empleo para los principales miembros de la Asociación; proveen los insumos para la subsistencia de los miembros y el dinero para seguir creciendo como asociación. Miembros que en su mayoría, antes de ser integrantes de ONG, han transitado por diferentes empleos en condiciones de precariedad e inestabilidad.

Por otra parte, el trabajo en los proyectos sin financiamiento y vinculado a los fines primarios de la asociación se reserva para los voluntarios, entre ellos los llamados "pasantes", alumnos avanzados de diferentes carreras universitarias, entre ellas, Trabajo Social.

\section{Condiciones de trabajo de miembros de las ONG:}

En general las condiciones de trabajo de técnicos, profesionales y personal de apoyo en estas organizaciones se caracteriza 
por regirse mediante contratos sin relación de dependencia, partime, por tiempo limitado y sin garantías de continuidad; con flexibilidad horaria; bajos ingresos; exigencia de compromiso previo y sin aspiración de ingresos a corto plazo como condición para acceder; predisposición a utilizar sus propios recursos, con fuertes dosis de trabajo voluntario; llevando todo esto a las consecuentes implicancias en la cobertura de la seguridad social y de aportes previsionales.

Las condiciones laborales en que se desempeñan los agentes (técnicos-profesionales y otros) en estas organizaciones muestran claramente la precarización y flexibilización de las relaciones laborales y, por otro lado, la trasferencia de responsabilidades y costos de la intervención sobre la cuestión social, desde el Estado hacia las ONG, implicando una terciarización de la política social.

\section{La relación entre Estado y ONG}

Del análisis de la información se desprende que uno de los roles del Estado en relación a los programas de política social que manejan las ONG es el diseño de las líneas de acción financiables, que en general prescriben el problema, las alternativas de solución, el perfil del usuario, y las normas y requisitos para constituirse en receptoras de fondos del Estado (entre ellos el asociativismo como pre-condición) y las exigencias en la presentación y aprobación de los proyectos.

La prescripción del problema y la solución, presupone una capacidad instalada entre los usuarios sobre conocimientos de planificación y accionar empresarial y prácticas de asociativismo; además de pautar cambios en la dinámica cotidiana de los grupos familiares para poder ser receptores de los beneficios y servicios; así también establece categorías de beneficiarios altamente estigmatizantes, contradiciendo así la idea de desarrollo local que se plantea como uno de los ejes de la política social.

En la relación Estado-ONG, se identifican una serie de dificultades a la hora de la institucionalización y puesta en funcionamiento de la organización. Entre las dificultades se menciona el exceso de burocracia, la desarticulación de acciones y normativas entre los ámbitos nacional - provincial y municipal; las diferencias de criterios entre las jurisdicciones en cuanto a las formas de asignar 
los recursos, formas de operar, entre las cuales se destacan las diferencias de criterios a la hora de evaluar la viabilidad y factibilidad de los proyectos financiables.

Desde las ONG, el Estado es visto como un ente burocrático, lento, que no fiscaliza in situ las acciones, solo vela que se cumpla con la forma y con la normativa. Se lo ve como ineficiente, que llega tarde con los fondos, que desconoce el problema social, por tener fundamentalmente sus técnicos en las oficinas y no en la calle donde están los problemas. Además de ser visto como un ente que consume una gran parte del monto del dinero destinado a lo social, en tareas de supervisión de fondos, a la vez que fomenta las relaciones clientelares a la hora de seleccionar los beneficiarios y a través de sus planes promueve actitudes desestimulantes al trabajo.

En contraposición a las percepciones que las ONG tienen del Estado, éstas se autodefinen como pragmáticas, sacrificadas, haciendo todo a pulmón; conocedores del los problemas y necesidades de la gente, "las asociaciones llegan más porque tocan tierra", ven los problemas más de cerca y deben adecuar la solución a los programas enlatados que bajan.

Por su parte, desde estas organizaciones el usuario es visto como el desvalido, desprovisto, como aquel que tuvo mala suerte en la vida, pero por otro lado, acostumbrado a "sentarse y esperar que vos le traigas el pan, la bolsa, el plan techo que vos le traigas... los tipos no quieren salir adelante en algunos casos. (Referente ONG 1). Algunos son emprendedores y otros no y tenemos que ayudarlos... (Referente ONG 2).

Los atributos depositados en la idea de usuario son adjudicados al Estado como el responsable de fomentarlos a partir de las relaciones clientelares. "...quien los mal acostumbra es el Estado..." (Referente ONG 1).

Los técnicos son vistos como recursos humanos expertos en lo organizacional, conocedores de la burocracia, como los entendidos, gestores de proyectos, con autonomía para gestionar recursos, como actores necesarios para abordar la diversidad de ofertas de proyectos posibles de ser canalizados desde las ONG. A pesar de todas las características ponderadas positivamente, también son considerados con limitaciones por ceñirse a lo teórico y contar con escasa práctica, con escasas habilidades para trabajar con la gente. 
Entre los técnicos son ubicados también los trabajadores sociales, a quienes se los considera como los conocedores de los ámbitos / programas donde se pueden gestionar recursos. Asimismo, se establece una diferenciación entre profesionales de vocación y sin vocación. Siendo los profesionales de vocación aquellos que muestran compromiso desinteresado y que no les importa recibir una remuneración ("el trabajador social auténtico") y se involucran en los proyectos de trabajo de las asociaciones. A diferencia de otro tipo de trabajador social que busca obtener un salario sin comprometerse con la atención de la cuestión social y en muchos casos utilizando a la cuestión social y la alternativa de las ONG para posicionarse mejor profesionalmente y económicamente.

Desde las ONG se apunta como una de las dificultades y limitaciones, que los profesionales pretendan establecer una relación contractual similar a la que establece el Estado, esto es un trabajo con relación de dependencia que permita estabilidad y la cobertura de la seguridad social.

A diferencia de los profesionales, para una parte importante de los estudiantes de trabajo social, que desarrollan experiencias en el ámbito de una ONG constituye una forma de dar continuidad al trabajo que se inicia en la etapa de la formación pre - profesional en diferentes instituciones del Estado. La experiencia pre profesional en instituciones del Estado posibilita la aproximación y conocimiento más particularizado de un campo específico del ejercicio profesional y la construcción de relaciones con agentes del campo, que el estudiante capitalizará al insertarse en una ONG.

\section{Conclusiones:}

El contexto económico y social de retracción de derechos sociales, ocurrido en la década del '90 funcionó como un disparador para la terciarización de la política social, que crecientemente comenzó a ser operacionalizada, en un principio, a partir del trabajo voluntario realizado a través de las organizaciones del tercer sector. Estas organizaciones surgieron y se desarrollaron como prestadoras de programas de política social, transformando el recurso público en capital simbólico y económico, mediante los cuales se posicionaron y legitimaron como institución en el campo de las políticas sociales. 
Coincidentemente con los cambios registrados en los Estados de Bienestar, estas organizaciones focalizan su accionar en dar cobertura a las necesidades de los sectores vulnerables de la población afectadas por la reconfiguración de la cuestión social y el desentendimiento del Estado. Así, a partir de su accionar, prescripto por las líneas de política social financiables desde el Estado, van a tratar de paliar diferentes necesidades básicas de la población, de forma focalizada y parcial, recuperando una serie de categorías muy utilizadas por el trabajo social (participación, concientización, formación, etcétera), sin poner en cuestión las relaciones de producción capital - trabajo.

El hecho de que la política social se operacionalice a través de las ONG, implicó un desplazamiento de la intervención sobre lo social encarada por el Estado, desde el campo del derecho social al de la intervención como un deber moral.

A pesar que desde el discurso las ONG son colocadas como garantes de la eficiencia y eficacia en la llegada de los recursos a los sectores más necesitados de la población, se observa que el hecho de que las políticas sociales se operacionalicen a partir de ellas, no las exceptúa de las mismas prácticas clientelares que antes se le atribuían al Estado.

En ese sentido, no garantizan relaciones democráticas, entendidas estas como formas de relación más horizontal y más igualitaria entre sus miembros, ya que los cargos directivos casualmente se concentran en las mismas personas "miembros de las ONG" y las instancias de participación y decisión colectivas (asambleas, comisiones de trabajo, etcétera) terminan siendo meros formalismos a cumplir para seguir sosteniéndose como organización.

Por otra parte, tampoco estarían garantizando que la mayoría de los recursos lleguen a los beneficiarios ya que las mismas organizaciones construyen estrategias para la captación de esos recursos para su propia subsistencia y desarrollo como organización y la de sus miembros.

Si bien representan formas de autoempleo tanto para técnicos como para trabajadores sociales, las condiciones son de absoluta precarización laboral, desde el punto de vista de los ingresos, la estabilidad en el empleo, la cobertura de la seguridad social. 
Nuevas formas de intervención en la cuestión social: la actuación de las organizaciones no gubernamentales en las políticas sociales en la ciudad de Posadas Misiones Argentina / Susana Moniec; Rosario González

\section{Referencias Bibliográficas}

AQUIN, N. (2000). La implicancia de los procesos de desciudadanización para el trabajo Social. Córdoba: Universidad Nacional de Córdoba

BobBio, N. y otros (1983). Diccionario de Política Social. 9a. ed. México: Ed. Siglo XXI.

BUSTELO, E. (2000). De otra manera. Ensayos sobre la política social y equidad. Buenos Aires: Homo Sapiens.

CARDARELLI, G., ROSENFELD, M. (2003). La gestión asociada en el campo de las políticas sociales: ¿Una utopía realista?. Buenos Aires: CEADEL.

CASTEL, R. (1995). La metamorfosis de la cuestión social. Buenos Aires: Paidós.

FAleiros, V. (1988). O que é a Política Social. São Paulo: Ed. Brasiliense.

GARCIA, S. (1991). Especificidad y rol en trabajo social. Buenos Aires: Humanitas.

GRASSI, E. (2003). Políticas y problemas sociales en la sociedad neoliberal. La otra década infame. Buenos Aires: Espacio.

HintZe, S. y CORAGGiO, J. (1996). Políticas Sociales. Contribución al debate teórico metodológico. Buenos Aires: Eudeba.

HINTZE, S. (1996). Políticas Sociales. Contribución al debate teórico metodológico. Buenos Aires: Eudeba.

MALACALZA, S. (2000). Las políticas sociales en los umbrales del siglo XXI. Buenos Aires: Eudeba.

(1994). Pensando el Trabajo Social en este final de siglo. Margen, (5).

ROZAS P., M. (2001). La intervención profesional en relación con la cuestión social. Buenos Aires: ESPACIO.

WOLFE, A. (1994). Três caminhos para o desenvolvimento: estado, mercado e sociedade civil. Rio de Janeiro: IBASE, PNUD. 